\title{
Effect of final irrigation protocols on microhardness reduction and erosion of root canal dentin
}

\section{Flávia Emi Razera BALDASSO(a) Luana ROLETO(a) \\ Vinicius Duval da SILVA ${ }^{(b)}$ \\ Renata Dornelles MORGENTAL (c) \\ Patrícia Maria Poli KOPPER ${ }^{(a)}$}

(a) Universidade Federal do Rio Grande do Sul - UFRGS, School of Dentistry, Department of Conservative Dentistry, Porto Alegre, RS, Brazil.

(b)Pontifícia Universidade Católica do Rio Grande do Sul - PUC-RS, School of Medicine, Department of Pathology, Porto Alegre, RS, Brazil.

(c) Universidade Federal de Santa Maria - UFSM, Department of Stomatology, Santa Maria, RS, Brazil.

Declaration of Interest: The authors certify that they have no commercial or associative interest that represents a conflict of interest in connection with the manuscript.

Corresponding author:

Flávia Emi Razera Baldasso

E-mail: fla_erb@hotmail.com

https://doi.org/10.1590/1807-3107BOR-2017.vol31.0040

Submitted: Oct 17, 2016

Accepted for publication: Mar 21, 2017

Last revision: Apr 10, 2017
Abstract: This study aimed to evaluate the effect of final irrigation protocols on microhardness reduction and erosion of root canal dentin. Sixty root canals from mandibular incisors were instrumented and randomly divided into six groups $(n=10)$ according to the irrigant used: QMiX, 17\% EDTA, 10\% citric acid (CA), 1\% peracetic acid (PA), $2.5 \% \mathrm{NaOCl}$ (solution control), and distilled water (negative control). The chelating solutions were used to irrigate the canal followed by $2.5 \%$ $\mathrm{NaOCl}$ as a final flush. After the irrigation protocols, all specimens were rinsed with $10 \mathrm{~mL}$ of distilled water to remove any residue of the chemical solutions. Before and after the final irrigation protocols, dentin microhardness was measured with a Knoop indenter. Three indentations were made at $100 \mu \mathrm{m}$ and $500 \mu \mathrm{m}$ from the root canal lumen. Afterwards, the specimens were prepared for scanning electron microscopic analysis and the amount of dentin erosion was examined. Wilcoxon and Kruskal-Wallis tests were used to analyze the results with a significance level set at 5\%. At $100 \mu \mathrm{m}$, all protocols significantly reduced dentin microhardness ( $p<05)$, while at $500 \mu \mathrm{m}$, this effect was detected only in the EDTA and QMiX groups $(p<.05)$. CA was the irrigant that caused more extensive erosion in dentinal tubules, followed by PA and EDTA. QMiX opened dentinal tubules, but did not cause dentin erosion. Results suggest that QMiX and 17\% EDTA reduced dentin microhardness at a greater depth. Additionally, QMiX did not cause dentin erosion.

Keywords: Endodontics; Root Canal Irrigants; Hardness; Erosion.

\section{Introduction}

Root canal cleaning and disinfection are critical factors for a successful endodontic therapy. Therefore, chemical auxiliary agents are necessary in inaccessible areas of the root canal system ${ }^{1}$ for periapical tissue repair. ${ }^{2}$

The smear layer is an amorphous film that is always formed by the action of endodontic instruments inside the root canal during chemomechanical preparation. ${ }^{3,4}$ Since this residual layer can influence root canal filling quality, different techniques and solutions have been used and tested for its removal. ${ }^{4,5}$ Chelating agents have been suggested for removal of the smear layer, ${ }^{6,7}$ as well as for demineralization and softening of root dentin. ${ }^{8}$ However, demineralization may have a negative influence on the chemical and structural composition of dentin. ${ }^{8}$ 
The most widely used chelating agents are based on different concentrations of ethylenediaminetetraacetic acid (EDTA). ${ }^{9}$ In addition to EDTA, other chelating solutions have been studied, such as peracetic and citric acids. ${ }^{10}$ These solutions can remove dentin calcium ions, ${ }^{8,10}$ favoring smear layer removal. ${ }^{6,11}$ However, it is known that such chemical auxiliary substances are responsible for reaching the inorganic structure of dentin and thereby cause changes in dentin microhardness ${ }^{8,12,13}$ and erosion. ${ }^{12,14,15,16}$ Some studies have suggested that these changes could increase the susceptibility to tooth fracture. ${ }^{17}$

A solution known as QMiX has been suggested in the literature. This irrigant is ready for use and contains EDTA, chlorhexidine, and a detergent, with a slightly alkaline $\mathrm{pH} \cdot{ }^{18,19} \mathrm{QMiX}$ is recommended after the use of sodium hypochlorite $(\mathrm{NaOCl})$ during root canal instrumentation ${ }^{18,19}$ and is effective in removing the smear layer. ${ }^{18-20}$

Therefore, the present study aimed to evaluate the effects of QMiX, 17\% EDTA, 10\% citric acid (CA), 1\% peracetic acid (PA), $2.5 \% \mathrm{NaOCl}$ (solution control), and distilled water (negative control) on microhardness reduction and erosion of human root canal dentin. The null hypothesis is that no irrigation protocol reduces microhardness or causes erosion in human root canal dentin.

\section{Methods}

This study was approved by the Research Ethics Committee of the School of Dentistry of the Federal University of Rio Grande do Sul, Porto Alegre, Brazil (CAAE 37254314300005347).

Sixty mandibular single-rooted human incisors extracted for periodontal reasons were selected for this study. Following extraction, debris and soft tissue remnants in the root were cleaned with a sharp scalpel and the teeth were washed with $0.9 \%$ sterile saline solution (Texon, Viamão, Brazil). Thereafter, the teeth were stored in distilled water until their use in the experiments.

Dental crowns and apices were sectioned with a high-speed diamond bur (KGSorensen, Cotia, Brazil) under water cooling. Only a 6-mm-long segment from the middle and apical parts of the root was used in the experiment. Each segment was mounted in an individual low-fusing compound device with acrylic resin and the dentin surface was polished with silicon carbide sandpapers (3M, St. Paul, MN) with three progressively increasing grit sizes (400, 600 , and 1,200 ) to obtain a smooth surface without gradients. Final polishing was performed by felt discs (Buehler, Lake Bluff, USA) and the specimens were washed in running water. Root canals were then prepared by \#40.08 Large WaveOne ${ }^{\circledR}$ files (Dentsply Maillefer, Ballaigues, Switzerland), according to the manufacturer's instructions, and irrigated with distilled water.

Before application of the test solutions, dentin microhardness was measured with a Knoop indenter using 40× magnification (HMV-G; Shimadzu Corp., Tokyo, Japan) under a 10-gram load and a 20-second dwell time. Three indentations were made at $100 \mu \mathrm{m}$ and three at $500 \mu \mathrm{m}$ from the root canal lumen. The representative hardness value for each specimen at each distance was obtained as the average of the three indentations. All specimens were then randomly divided into six groups $(n=10)$ according to the irrigation protocol:

a. QMiX group - Irrigation with QMiX (Dentsply Tulsa Dental Specialties, Johnson City, TN) for 2 min followed by $2.5 \% \mathrm{NaOCl}$ (CIENTEC- Science and Technology Foundation, Porto Alegre, Brazil) for 5 min;

b. EDTA group - Irrigation with 17\% EDTA (CIENTEC - Science and Technology Foundation, Porto Alegre, Brazil) followed by $2.5 \% \mathrm{NaOCl}$, both for $5 \mathrm{~min}$;

c. CA group - Irrigation with $10 \%$ citric acid (CIENTEC-Science and Technology Foundation, Porto Alegre, Brazil) followed by $2.5 \% \mathrm{NaOCl}$, both for 5 min;

d. PA group - Irrigation with $1 \%$ peracetic acid (CIENTEC- Science and Technology Foundation, Porto Alegre, Brazil) followed by $2.5 \% \mathrm{NaOCl}$, both for $5 \mathrm{~min}$;

e. $\mathrm{NaOCl}$ group (solution control group) - Irrigation with $2.5 \% \mathrm{NaOCl}$ for $5 \mathrm{~min}$;

f. DW group (negative control) - Irrigation with distilled water for $5 \mathrm{~min}$. 
Irrigation was carried out using Endo-Eze ${ }^{\circledR} 30 \mathrm{G}$ needles (Ultradent Products Inc., South Jordan, UT) attached to 10-mLdisposableplastic syringes (BD-Becton Dickinson, São Paulo, Brazil), along with suction. The suction cannula was maintained next to the canal, preventing it from spreading over the root surface. Every minute, $2 \mathrm{~mL}$ of the respective solution was dispensed into the canal. After the irrigation protocol, all specimens were rinsed with $10 \mathrm{~mL}$ of distilled water to remove any residue of the chemical solutions.

Next, a new microhardness measurement was performed as previously described. The difference between initial and final microhardness values was calculated to obtain the microhardness difference observed in each protocol.

The specimens were then split longitudinally and one half of each specimen was dehydrated, mounted on stubs, gold sputtered, and evaluated under a scanning electron microscope (SEM) (Phillips XL-30, Eidhoven, Netherlands) operated at $9 \mathrm{kV}$. Photomicrographs were taken at 2000× magnification. One blinded and calibrated observer (kappa $=0.88$ ) classified erosion in each image according to the following criteria, adapted from Torabinejad et al. ${ }^{14}$ score $0=$ smear layer covering almost all dentin surface, with few or no opened tubules; score 1 = no erosion: all tubules looked normal in appearance and size; score 2 = moderate erosion: the peritubular dentin was eroded; score 3 = severe erosion: the intertubular dentin was destroyed and the tubules were connected to each other. The area to be analyzed was selected randomly, with a lower magnification (200×). Afterwards, magnification was increased (2000x) without moving the microscope and the first image was captured. Other four areas were selected around the first field chosen by moving the microscope up, down, right, and left.

Microhardness data before and after final irrigation were compared by Wilcoxon's test, in each group, at each depth. The same test compared microhardness reduction between $100 \mu \mathrm{m}$ and $500 \mu \mathrm{m}$ points in each group. The Kruskal-Wallis test, followed by Dunn's test, was applied for comparison among groups regarding microhardness reduction at each distance and erosion of dentinal tubules. The significance level was set at 5\%.

\section{Results}

Differences in dentin microhardness before and after final irrigation and between groups, at the same distance, are summarized in Figure 1. At $100 \mu \mathrm{m}$, all protocols significantly reduced dentin microhardness $(\mathrm{p}<.05)$, while at $500 \mu \mathrm{m}$, this effect was detected only in the EDTA and QMiX groups ( $<$.05). There was no significant difference in microhardness reduction between $100 \mu \mathrm{m}$ and $500 \mu \mathrm{m}$ in each group.
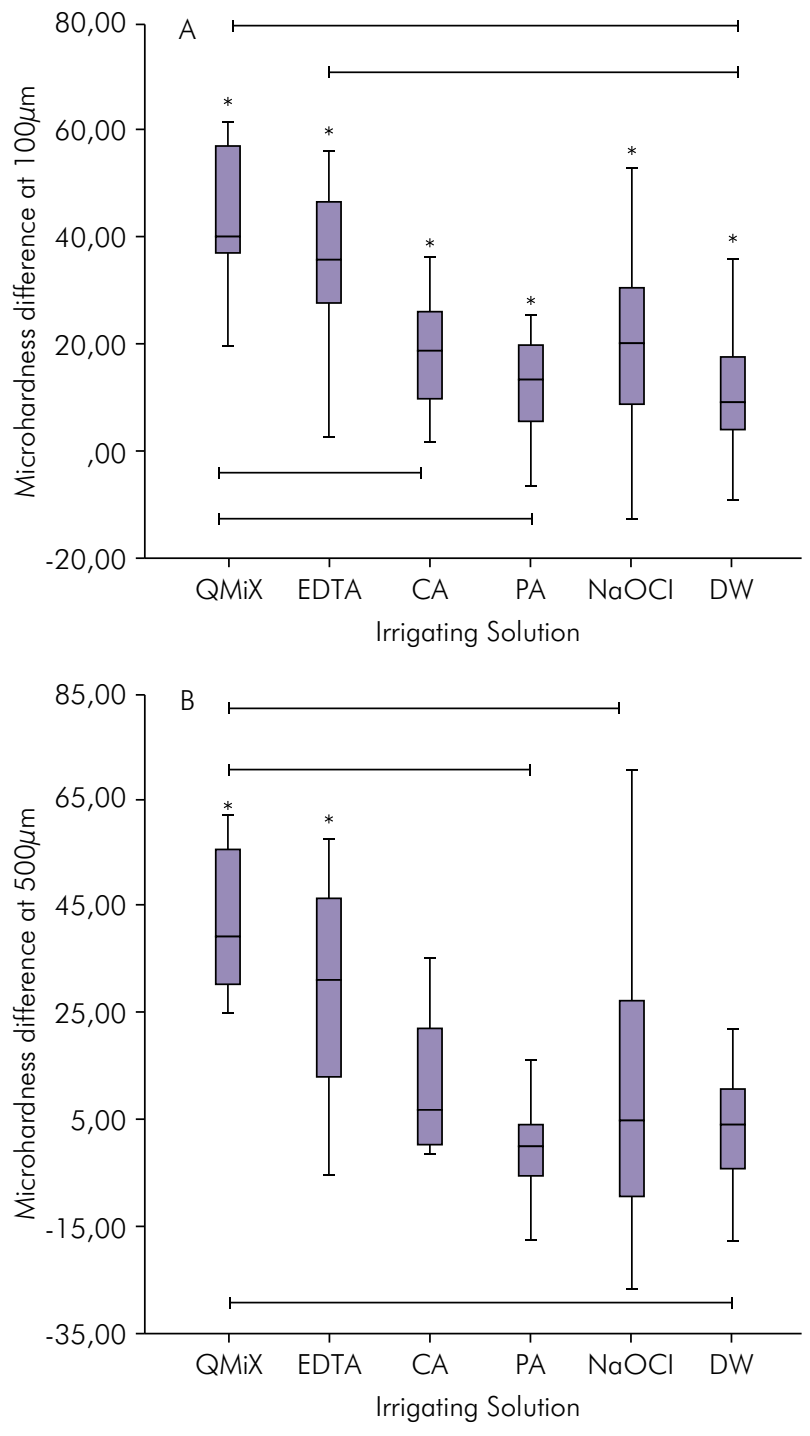

Figure 1. Box-plot comparing microhardness differences at $100 \mu \mathrm{m}(\mathrm{A})$ and $500 \mu \mathrm{m}(\mathrm{B})$. The asterisk indicates statistically significant difference before and after irrigation protocols $(p<.05)$. The horizontal bar indicates statistically significant difference between groups at the same distance $(p<.05)$. 
Erosion results are summarized in Table 1. The DW and $\mathrm{NaOCl}$ groups (Figures $2 \mathrm{E}$ and $2 \mathrm{~F}$, respectively) were not able to remove the smear layer, and dentinal tubules appeared obliterated. The CA (Figure 2C) group scored higher for erosion in dentinal tubules, followed by the PA (Figure 2D) and EDTA (Figure 2B) groups. The QMiX group (Figure 2A) opened the dentinal tubules, but did not cause dentin erosion.

\section{Discussion}

The null hypothesis of the present study was rejected, as some tested protocols significantly reduced dentin microhardness and caused erosion in human root canal dentin.

Scanning electron microscopic studies have shown that bacteria can colonize various regions of the root canal system, including dentinal tubules, isthmus, and other irregularities, i.e., areas of difficult access for endodontic instrumentation..$^{21,22}$ A previous study showed that some canal irrigants could penetrate up to $130 \mu \mathrm{m}$ from the canal lumen and eliminate bacteria. ${ }^{23}$ However, heavy bacterial infection inside dentinal tubules may be present at depths of $400 \mu \mathrm{m} \cdot{ }^{24}$ For this reason, the present study evaluated reduction in dentin microhardness at $100 \mu \mathrm{m}$ and $500 \mu \mathrm{m}$ from the canal lumen, similarly to the study of Saghiri et al. ${ }^{12}$

Table 1. Median and 25th and 75th percentiles of the erosion score after the irrigation protocols.

\begin{tabular}{lcccccc}
\hline Variable & QMiX & EDTA & CA & PA & NaOCl & DW \\
\hline Median & $1^{\text {bc }}$ & $1.5^{\text {ab }}$ & $3^{a}$ & $2^{a b}$ & $0^{c}$ & 0 \\
Percentiles & & 1 & 2 & 1 & 0 & 0 \\
25 & 1 & 2 & 3 & 2 & 0 & 0 \\
75 & 1 & 1 & 2 & 0 \\
\hline
\end{tabular}

*Different letters denote significant differences after the Kruskal-Wallis and Dunn's post-hoc tests $(\alpha<.05)$
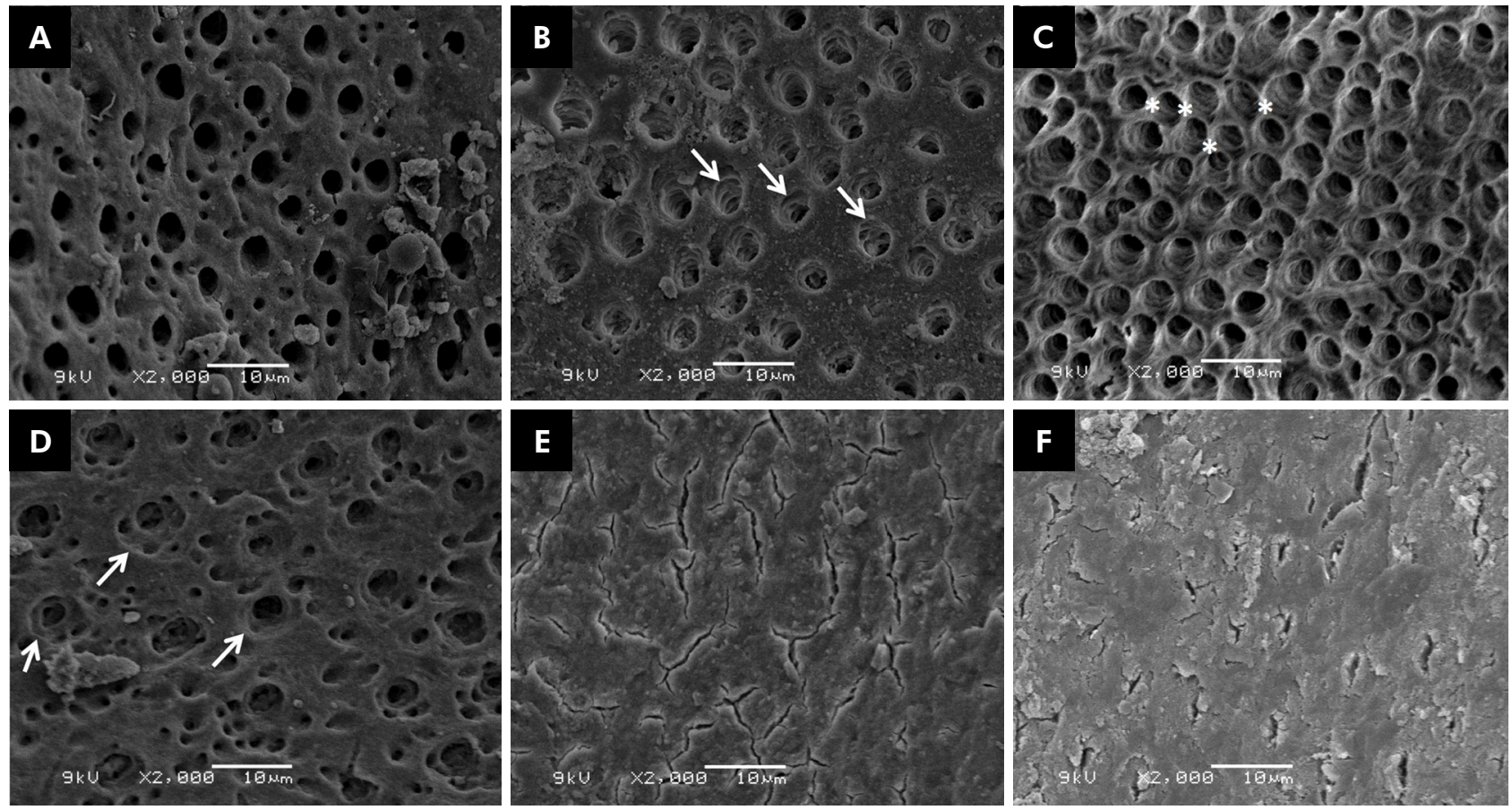

Figure 2. SEM images $(2000 \times)$ illustrating the effects caused by irrigation protocols on the inorganic component of dentin. (A) QMiX group - score 1, no erosion, all tubules looked normal in appearance and size; (B) EDTA and (D) PA groups - score 2, the arrows indicate erosion in peritubular dentin; (C) CA group - score 3, the intertubular dentin was destroyed and the asterisks indicate tubules connected to each other $\left({ }^{*}\right) ;(E) \mathrm{NaOCl}$ and $(F)$ DW groups - score 0 , smear layer covering the entire dentin surface. 
In previous studies, the Vickers indenter method was used for measuring dentin hardness., ${ }^{8,22}$ Fuentes et al. ${ }^{26}$ determined the microhardness of superficial and deep dentin by means of two indentation methods (Knoop and Vickers) under two different applied loads. Knoop hardness was significantly higher for superficial dentin than for deep dentin, ${ }^{26}$ presenting sensitivity to surface effects and textures ${ }^{13}$ suggesting that superficial dentin, closer to the pulp, should be analyzed with this method. ${ }^{27}$ As in the present study, the Knoop indenter was used in previous investigations to evaluate changes in dentin microhardness. ${ }^{13,27}$

Some studies in the literature have evaluated changes in dentin microhardness after canal irrigation with different solutions. ${ }^{8,13,25}$ However, they have not evaluated initial microhardness, which may render the results imprecise, since the teeth have different initial physical characteristics. In the present study, the average of the three indentations at $100 \mu \mathrm{m}$ and $500 \mu \mathrm{m}$ before irrigation was obtained to provide a representative value of the initial microhardness of each specimen. Moreover, in the present investigation, the solution was taken to the canal with the help of a syringe coupled to the irrigation needle, being simultaneously aspirated, thus simulating clinical practice.

At $100 \mu \mathrm{m}$, all protocols significantly reduced Knoop microhardness; EDTA and QMiX promoted the largest reduction (Figure 1A). These results are in agreement with those of several previous studies, $, 12,27,28,29$ in which these solutions also reduced microhardness. This effect is desirable in the layer next to the canal lumen and it has been associated with increasing calcium loss, resulting in dentin demineralization and softening. ${ }^{8}$ The use of chelating agents for final irrigation removes the smear layer and reduces dentin microhardness, which increases the access of the irrigant to dentinal tubules, allowing for proper disinfection. ${ }^{13}$

However, the effects of such calcium loss on tooth fracture resistance and on the adhesion of endodontic sealers deserve clinical attention. It has been suggested that, although chemical substances can reduce tooth hardness, this change in hardness does not interfere with substrate resistance. ${ }^{30}$ By contrast, Uzunoglu et al. ${ }^{17}$ showed that fracture resistance of endodontically treated roots was differently affected by the various EDTA concentrations, followed by irrigation with $\mathrm{NaOCl}$, at different exposure times.

At $500 \mu \mathrm{m}$, only the EDTA and QMiX groups significantly reduced Knoop microhardness (Figure1B). Thus, these solutions may penetrate deeper into the dentin, positively interfering in sealer penetration during root canal system filling procedures. Along the same line, previous investigations showed that $\mathrm{QMiX}^{31}$ and EDTA ${ }^{32}$ improved sealer penetration when compared to $2.5 \% \mathrm{NaOCl}$. Jardine et al. ${ }^{33}$ observed that EDTA and QMiX promoted deeper sealer penetration than that achieved by BioPure MTAD, which contains citric acid. Once QMiX contains EDTA in its composition, a similar behavior is expected from these solutions.

Dentin erosion caused by irrigants has been widely studied in the literature ${ }^{16,28}$ and is associated with the use of $\mathrm{NaOCl}$ after irrigation with the chelating solution. When $\mathrm{NaOCl}$ is used before EDTA, the hydroxyapatite coating seems to protect the collagen fibers from the dissolving action of $\mathrm{NaOCl}^{16}$ Once $\mathrm{NaOCl}$ is used subsequently to the chelating solutions, it can directly attack collagen, which was previously exposed by the demineralizing agent. ${ }^{16}$ In this context, this study aimed to evaluate only dentin erosion and microhardness changes that could occur after the final flush of the root canal (chelating agent $+\mathrm{NaOCl}$ ); hence, distilled water was used as irrigant during root canal preparation.

In the present investigation, the EDTA, CA, and PA groups were effective in removing the smear layer and opening dentinal tubules (Figures 2B, 2C, 2D). However, these protocols caused erosion in dentinal tubules, which is in agreement with other studies. ${ }^{12,16}$ Qian et al. ${ }^{16}$ suggest that dentin erosion may contribute to vertical root fracture. On the other hand, erosion can also help optimize the cleaning of the canal wall, eliminating debris and bacteria from the endodontic space. ${ }^{16,34}$

Although the CA and PA groups caused greater erosion in dentinal tubules when compared to the EDTA and QMiX groups, these solutions did not significantly change microhardness at $500 \mu \mathrm{m}$. According to Saghiri et al., ${ }^{12}$ erosion is not the main cause of reduction in dentin hardness, as the depth of irrigant penetration might be the key factor. This can be explained by different demineralization 
patterns caused by irrigating solutions. ${ }^{6,10}$ Lottanti et al. ${ }^{6}$ observed that EDTA enlarged the opening of tubules at the canal wall and decalcification occurred along the tubular walls, while the use of PA led to fewer decalcified areas in the tubules.

According to the literature, $\mathrm{QMiX}$ is an effective irrigant that can remove the smear layer and open dentinal tubules after acting inside the root canal for 2 min. ${ }^{18,19,28,35} \mathrm{QMiX}$ was able to open dentinal tubules without causing erosion (Figure 2A). These findings are in agreement with those of previous studies and with the manufacturer. ${ }^{20,28}$ Although dentin erosion is associated with the use of $\mathrm{NaOCl}$ after irrigation with the chelating solution, ${ }^{16} \mathrm{QMiX}$ was finally flushed with $\mathrm{NaOCl}$ and did not cause erosion, but changed microhardness at $500 \mu \mathrm{m}$. The combined actions of chlorhexidine and cetrimide (a detergent) present in $\mathrm{QMiX}^{32,36}$ may be responsible for the alteration in microhardness at $500 \mu \mathrm{m}$, since these components increase the irrigation of root canal dentin. ${ }^{32}$ Moreover, according to Poggio et al., ${ }^{37}$ the association of cetrimide with EDTA did not affect decalcifying ability of the latter. The detergent may be responsible for facilitating
EDTA penetration into dentinal tubules, causing reduction in microhardness at a greater depth and avoiding EDTA's superficial action, which causes erosion. Therefore, QMiX seems to have important and good characteristics as a chelating agent and should be considered for clinical use.

\section{Conclusions}

Based on the experimental methods and results, it can be concluded that QMiX and 17\% EDTA reduced dentin microhardness at a greater depth when compared to $10 \%$ CA and 1\% PA. Additionally, and differently from EDTA 17\%, QMiX did not cause dentin erosion.

\section{Acknowledgments}

The authors would like to thank the "Centro de Microscopia e Microanálise" (CMM) of the Federal University of Rio Grande do Sul for making the SEM analysis possible. The authors deny any conflicts of interest related to this study.

\section{References}

1. Siqueira JF Jr, Rôças IN, Santos SR, Lima KC,

Magalhães FA, Uzeda M. Efficacy of instrumentation

techniques and irrigation regimens in reducing the bacterial population within root canals. J Endod. 2002;28(3):181-4. https://doi.org/10.1097/00004770-200203000-00009

2. Schilder H. Cleaning and shaping the root canal. Dent Clin North Am. 1974;18(2):269-96.

3. McComb D, Smith DC. A preliminary scanning electron microscopic study of root canals after endodontic procedures. J Endod. 1975;1(7):238-42. https://doi.org/10.1016/S0099-2399(75)80226-3

4. Sen BH, Wesselink PR, Türkün M. The smear layer: a phenomenon in root canal therapy. Int Endod J. 1995;28(3):141-8. https://doi. org/10.1111/j.1365-2591.1995.tb00289.x

5. George R, Meyers IA, Walsh LJ. Laser activation of endodontic irrigants with improved conical laser fiber tips for removing smear layer in the apical third of the root canal. J Endod. 2008;34(12):1524-7. https://doi.org/10.1016/i.joen.2008.08.029

6. Lottanti S, Gautschi H, Sener B, Zehnder M. Effects of ethylenediaminetetraacetic, etidronic and

peracetic acid irrigation on human root dentine and the smear layer. Int Endod J. 2009;42(4):335-43. https://doi.org/10.1111/j.1365-2591.2008.01514.x

7. Prado M, Gusman H, Gomes BP, Simão RA. Scanning electron microscopic investigation of the effectiveness of phosphoric acid in smear layer removal when compared with EDTA and citric acid. J Endod. 2011;37(2):255-8. https://doi.org/10.1016/j.joen.2010.11.011

8. Taneja S, Kumari M, Anand S. Effect of QMix, peracetic acid and ethylenediaminetetraacetic acid on calcium loss and microhardness of root dentine. J Conserv Dent. 2014;17(2):155-8. https://doi.org/10.4103/0972-0707.128058

9. Serper A, Calt S, Dogan AL, Guc D, Ozçelik B, Kuraner T. Comparison of the cytotoxic effects and smear layer removing capacity of oxidative potential water, $\mathrm{NaOCl}$ and EDTA. J Oral Sci. 2001;43(4):233-8. https://doi.org/10.2334/josnusd.43.233

10. Cobankara FK, Erdogan H, Hamurcu M. Effects of chelating agents on the mineral content of root canal dentin. Oral Surg Oral Med Oral Pathol Oral Radiol Endod. 2011;112(6):e149-54. https://doi.org/10.1016/j.tripleo.2011.06.037 
11. De-Deus G, Souza EM, Marins JR, Reis C, Paciornik S, Zehnder M. Smear layer dissolution by peracetic acid of low concentration. Int Endod J. 2011;44(6):485-90. https://doi.org/10.1111/j.1365-2591.2010.01847.x

12. Saghiri MA, Delvarani A, Mehrvarzfar P, Malganii G, Lotfi M, Dadresanfar $B$ et al. A study of the relation between erosion and microhardness of root canal dentin. Oral Surg Oral Med Oral Pathol Oral Radiol Endod. 2009;108(6):e29-34. https://doi.org/10.1016/j.tripleo.2009.07.056

13. Cruz-Filho AM, Sousa-Neto MD, Savioli RN, Silva RG, Vansan LP, Pécora JD. Effect of chelating solutions on the microhardness of root canal lumen dentin. J Endod. 2011;37(3):358-62. https://doi.org/10.1016/i.joen.2010.12.001

14. Torabinejad M, Khademi AA, Babagoli J, Cho Y, Johnson WB, Bozhilov $K$ et al. A new solution for the removal of the smear layer. J Endod. 2003;29(3):170-5. https://doi.org/10.1097/00004770-200303000-00002

15. Mai S, Kim YK, Arola DD, Gu LS, Kim JR, Pashley DH et al. Differential aggressiveness of ethylenediamine tetraacetic acid in causing canal wall erosion in the presence of sodium hypochlorite. J Dent. 2010;38(3):201-6. https://doi.org/10.1016/i.jdent.2009.10.004

16. Qian W, Shen Y, Haapasalo M. Quantitative analysis of the effect of irrigant solution sequences on dentin erosion. J Endod. 2011;37(10):1437-41. https://doi.org/10.1016/i.joen.2011.06.005

17. Uzunoglu E, Aktemur S, Uyanik MO, Durmaz V, Nagas E. Effect of ethylenediaminetetraacetic acid on root fracture with respect to concentration at different time exposures. J Endod. 2012 Aug;38(8):1110-3. https://doi.org/10.1016/i.joen.2012.04.026

18. Stojicic S, Shen Y, Qian W, Johnson B, Haapasalo $M$. Antibacterial and smear layer removal ability of a novel irrigant, QMiX. Int Endod J. 2012;45(4):363-71. https://doi.org/10.1111/j.1365-2591.2011.01985.x

19. Haapasalo M. The University of British Columbia, Vancouver (CA). Composition and method for irrigation of a prepared dental root canal. United States patent US 2012/0101166 A1. 2012 Apr 26.

20. Dentsply. QMix 2in1 irrigation solution. Tulsa: Dentsply; 2015 [acess 2015 May 17]. Available from: http://www.tulsadentalspecialties.com/default/ endodontics/activation/QMix.aspx

21. Alves FR, Siqueira JF Jr, Carmo FL, Santos AL, Peixoto RS, Rôças IN et al. Bacterial community profiling of cryogenically ground samples from the apical and coronal root segments of teeth with apical periodontitis. J Endod. 2009;35(4):486-92. https://doi.org/10.1016/i.joen.2008.12.022

22. Baldasso FE, Stürmer CP, Luisi SB, Petruzzi MN, Scarparo RK, De Figueiredo JA. Microflora associated with primary endodontic infections: correlations among SEM evaluation, clinical features, and radiographic findings. Microsc Res Tech. 2012;75(11):1557-63. https://doi.org/10.1002/jemt.22100

23. Berutti E, Marini R, Angeretti A. Penetration ability of different irrigants into dentinal tubules. J Endod. 1997;23(12):725-7. https://doi.org/10.1016/S0099-2399(97)80342-1
24. Haapasalo M, Orstavik D. In vitro infection and disinfection of dentinal tubules. J Dent Res. 1987;66(8):1375-9. https://doi.org/10.1177/00220345870660081801

25. Ghisi AC, Kopper PM, Baldasso FE, Stürmer CP, Rossi-Fedele G, Steier $L$ et al. Effect of super-oxidized water, sodium hypochlorite and EDTA on dentin microhardness. Braz Dent J. 2014;25(5):420-4. https://doi.org/10.1590/0103-6440201300129

26. Fuentes V, Toledano M, Osorio R, Carvalho RM. Microhardness of superficial and deep sound human dentin. J Biomed Mater Res A. 2003;66(4):850-3. https://doi.org/10.1002/jbm.a.10064

27. Tartari T, Souza PARS, Almeida BVN, Silva Junior JOC Pessoa OF, Souza Junior MHS. A new weak chelator in endodontics: effects of different irrigation regimens with etidronate on root dentin microhardness. Int J Dent. 2013;2013:ID743018. https://doi.org/10.1155/2013/743018

28. Aranda-Garcia AJ, Kuga MC, Chavéz-Andrade GM, Kalatzis-Sousa NG, Hungaro Duarte MA, Faria $G$ et al. Effect of final irrigation protocols on microhardness and erosion of root canal dentin. Microsc Res Tech. 2013;76(10):1079-83. https://doi.org/10.1002/jemt.22268

29. Das A, Kottoor J, Mathew J, Kumar S, George S. Dentine microhardness changes following conventional and alternate irrigation regimens: an in vitro study. J Conserv Dent. 2014;17(6): 546-9. https://doi.org/10.4103/0972-0707.144592

30. Marcelino AP, Bruniera JF, Rached-Junior FA, Silva SR, Messias DC. Impact of chemical agents for surface treatments on microhardness and flexural strength of root dentin. Braz Oral Res. 2014;28(1):28. https://doi.org/10.1590/1807-3107BOR-2014.vol28.0052

31. Kara Tuncer A. Effect of QMix 2in1 on sealer penetration into the dentinal tubules. J Endod. 2015;41(2):257-60. https://doi.org/10.1016/i.joen.2014.10.014

32. Kara Tuncer A, Tuncer S. Effect of different final irrigation solutions on dentinal tubule penetration depth and percentage of root canal sealer. J Endod. 2012;38(6):860-3. https://doi.org/10.1016/i.joen.2012.03.008

33. Jardine AP, Rosa RA, Santini MF, Wagner M, Só MV, Kuga MC et al. The effect of final irrigation on the penetrability of an epoxy resin-based sealer into dentinal tubules: a confocal microscopy study. Clin Oral Investig. 2016;20(1):117-23. https://doi.org/10.1007/s00784-015-1474-8

34. Niu W, Yoshioka T, Kobayashi C, Suda H. A scanning electron microscopic study of dentinal erosion by final irrigation with EDTA and $\mathrm{NaOCl}$ solutions. Int Endod J. 2002;35(11):934-9. https://doi.org/10.1046/j.1365-2591.2002.00594.x

35. Vemuri S, Kolanu SK, Varri S, Pabbati RK, Penumaka R, Bolla N. Effect of different final irrigating solutions on smear layer removal in apical third of root canal: A scanning electron microscope study. J Conserv Dent. 2016;19(1):87-90. https://doi.org/10.4103/0972-0707.173207 
- Effect of final irrigation protocols on microhardness reduction and erosion of root canal dentin

36. Assis DF, Prado M, Simão RA. Evaluation of the interaction between endodontic sealers and dentin treated with different irrigant solutions. J Endod. 2011;37(11):1550-2. https://doi.org/10.1016/j.joen.2011.08.014
37. Poggio C, Dagna A, Colombo M, Scribante A, Chiesa M. Decalcifying efficacy of different irrigating solutions: effect of cetrimide addition. Braz Oral Res. 2014;28:1-6. https://doi.org/10.1590/1807-3107BOR-2014.vol28.0047 